\title{
TECHNICAL EFFICIENCY OF OFFSHORE SUPPLY VESSEL ACCIDENT: A PARAMETRIC APPROACH
}

\author{
KASYPI MOKHTAR*, FITRI AL-AZIZI BAHAR, SITI MARSILA MHD RUSLAN, ANUAR \\ ABU BAKAR, LOKE KENG BIN, MOHD RIZAL ISMAIL AND WAN ZULHILMI ABDUL \\ HALIM
}

Faculty of Maritime Studies, Universiti Malaysia Terengganu, 21030 Kuala Nerus, Terengganu, Malaysia.

*Corresponding author: kasypi@umt.edu.my

http://doi.org/10.46754/jml.2021.08.005

\begin{abstract}
This study intended to measure accident rates based on human element since major accidents has led to large number of fatalities in shipping industry. For that purpose, Data Envelopment Analysis (DEA) is applied to test both cross sectional and panel data for each Decision-Making Unit (DMU). Additionally, this study used DEA-CCR model as well as variable method and the return to scale method (RTS) to provide a more comprehensive outcome. From the result, it is found that 5 vessels are efficiently operated, while 30 vessels are under-efficient. As a consequence, these 30 vessels need to revise their SOP on safety and current policies to boost their safety performance and awareness. Only from that, the vessels could reduce the occurrence of accident and able to operate efficiently and systematically.
\end{abstract}

Keywords: High risk operations, DEA, DMU, DEA-CCR, safety measures

\section{Introduction}

Shipping is probably the most international of all the world's great industries and one of the most dangerous International Maritime Organization (IMO) (2002). About 90 percent of world trade is carried out by shipping industry. There are about 53,000 merchant ships trading internationally, transporting several of cargoes, over 150 nations, and manned by over one million seafarers were registered in world shipping fleet (UNCTAD, 2019).

Shipping is considered as an economical, environmentally friendly and safe in a form of commercial transports. Number of accidents at sea shows a slow but steady decline in statistics during the last 10 years even though mediatisation draws public attention increasingly to accidents (Allianz Global Corporate and Specialty, 2013). Due to significant expansion in shipping industry which inherently leads to global maritime traffic, an increasing number of vessels potentially contribute to incidents and hazards (Baalisampang et al., 2018). Form of human error contributed to a large number of maritime accidents and incidents (Harati et al., 2006).
There are about 53,000 merchant ships trading internationally, transporting several of cargoes, over 150 nations, and manned by over one million seafarers were registered in world shipping fleet (UNCTAD, 2019).

The human contribution to maritime safety is well-studied in traditional shipping, form of risk, chain of events, and root causes that lead to incidents, and ultimately to accidents, vary significantly from what is encountered in offshore specialised vessels (Ismila et al., 2019). Standard maritime accident types such as grounding, collision due to navigation error, breakdown, fire, and explosion are all possible but unlikely in the sense of offshore. The key difference is that an offshore vessel engaged in offshore operations is often connected to a larger system, where technological or human error can result in power loss not only to the system but also to the vessel itself (Ismila et al., 2019). An engine stop on a tanker in the middle of the Atlantic Ocean can usually be repaired in a few minutes to a few hours, and if it is not repairable, the company and authorities can be notified, and a rescue operation can be scheduled and carried out. Consider the following scenario: a 
Semi-Submersible drilling rig is engaged in well completion operations and loses control. Due to the nature of the job, the device has seconds to minutes (time frame directly proportional to the degree of coupling and complexity) to regain full operating status, or an accident will occur.

\section{Marine Accident}

The IMO (1996) highlights the words "maritime accident," "maritime incident," and "maritime casualty" refer to unfavourable incidents that occur as a result of ship operations. However, the term "marine incident" refers to unfavourable marine events like collisions, injuries, and nearmisses event (Weintrit, 2009). Marine accident, in a broad sense, implies unusual and unwanted event that causes life threatening consequences, property and the environment. Emergency events are divided to those that do not cause harmful effects, but accidents can also cause or directly cause the death of people, endangering health, material damage at sea or ashore, pollution and other effects.

Hanzu-Pazara et al. (2008) state 75-96 percent of marine accidents are caused, at least in part, by some form of human error. They indicated that human error contributed to 89-96 percent of collisions, 75 percent of explosions, 79 percent of ground connections and 75 percent of allisions. Maritime accidents negatively affect men, the marine environment, properties and activities aboard ships and ashore in various forms and extent. The consequences of accidents range from minor injuries to death and from minor damage to very serious damage to environment and property. The cost of accidents, including the dead and injuries, damage to property and the environment, prevention and mitigation measures and insurance accounts for a significant share of transportation costs (Mullai \& Paulsson, 2011).

Any accident on a ship, regardless of its nature, is a nightmare. If this happens in a confined space, for example in a canal or strait, where traffic is intensive, several serious risks are possible. On the other hand, a large ship accident becomes even more critical. The ingress of water could impair the stability of a ship's condition. This would even exacerbated by severe weather or strong currents, and create "ecological" issue due to the oil spillage event (Akten \& Gonencgil, 2002). In the age of accurate navigation and satellite era, many victims still can be found at sea. Mankabady (1987); Krintiansen (2004) states cause of marine accidents injuries or loss of life, environmental damage, financial losses, social and legal; Akten (2006) states natural phenomenon, technical failures, route conditions, ship-related, human errors and cargo-related.

\section{Human Element and Competency}

Drucker (1985) defined competence at individual level as "an ability of an employee to offer superior performance in assigned tasks". Boyatzis et al. (2002) competence is "an underlying characteristic of a person, motives, traits, abilities, aspects of image or social role, knowledge that a person is able to use". Spencer and Spencer (1993) presented the following concept of competence: "it is an ability to perform well in terms of qualification, skills and knowledge, to have authority to do something, highly qualified awareness". Carr (2000) founded that good professional performance requires the practical application of individual abilities characterised by practical skills and attitudes.

Behavioural competencies are below the surface; they are more difficult to evaluate and, in many cases, to create. Behavioural competencies are expressions of how a person sees himself (self-image), how he or she normally acts (traits), and what motivates him or her (Carr, 2000). An iceberg is used to illustrate the definition of competency in the iceberg model for competencies. Just one-ninth of an iceberg's volume is visible above water, with the remainder submerged under the sea's surface. Similarly, certain behavioural components of a competency are evident, such as knowledge and skills, while others, such as attitude, traits, thought patterns, self-image, organisational fit, 
and so on, are obscured or lie underneath the surface (Spencer and Spencer, 1993).
Figure 1 shows the Iceberg Model wherein technical competencies are at the tip - the portion above the waterline that is clearly visible.

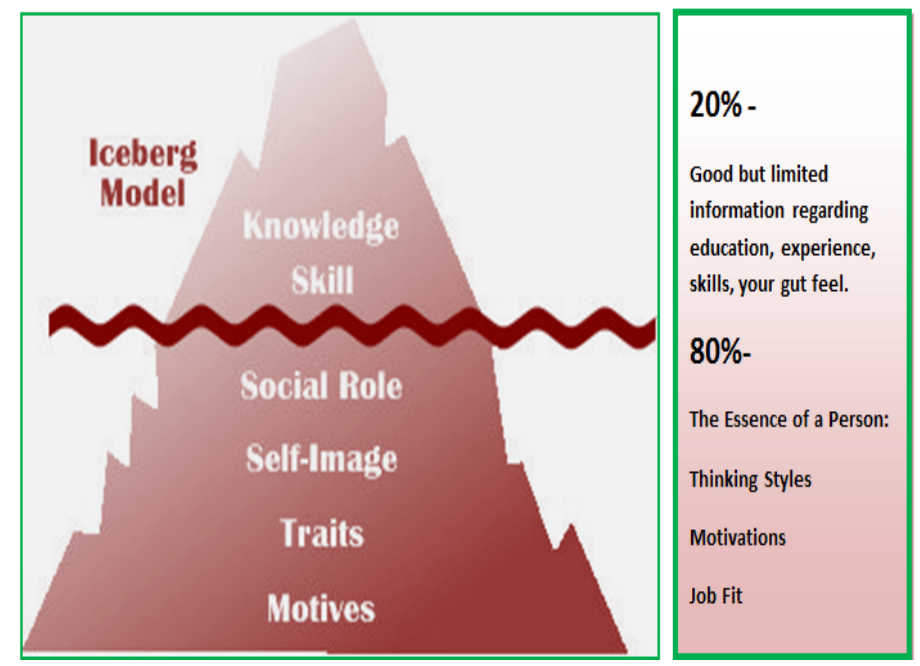

Figure 1: The iceberg model of competencies

Source: Spencer and Spencer (1993)

Employees that have a high degree of self-efficacy have a high level of perceived competence mobilisation. To feel competent as an employee, one must be comfortable with themselves and their skill set, as well as the ability to put those skills to use. Competence as it is perceived Mobilization is often linked to intrinsic motivation in a positive way. Employees' feelings of self-efficacy and intrinsic motivations will rise if they believe they can use their competencies and skillsets most effectively and that they are valuable to the company. As a result, higher levels of success can be achieved. (Lai, 2011).

It is critical to have not only administrators with strong visions, experience, and administrative skills, but also efficient employees who serve as the main mechanism for assisting administrators in achieving the organisation's goals, as described in the organization's mission. (Chansiri, 2008).

Organisations at all levels, from regional to multinational, have become increasingly successful in the globalised world. Competencies are critical factors impacting an organisation's competitiveness (Chansiri, 2008). As a result, it is essential for organisations to understand what makes effective management system.

Analyzing an individual's or a team's efficiency, acquiring high-performing workers, and recognising the requisite skills that employees must possess are all key factors that will assist the organisation in achieving its target. Greengard (1999) and McCleland (1973) mentioned that a person's IQ, which is made up of aptitude, academic abilities, experience, and a desire to succeed, is not a strong predictor of job performance, but it is competence.

This clearly demonstrates that a successful worker is not always a person with superior expertise, but rather a person who understands how to apply that knowledge to his job in order to maximise the benefits and effectiveness of his efforts. As a result, such an individual can be considered job competent. An individual with strong life management skills has a high level of competence. 


\section{Data Envelopment Analysis}

The Data Envelopment Analysis (DEA) methodology has significantly developed becoming an influential tool in benchmarking analysis. This progression is justified by the ease of model utilization and the possibility of applying multiples inputs and outputs. This method has been widely used in many areas from health, education, banking, ports, among others (Monteiro, 2015). DEA is a non-parametric linear programming method for estimating production efficiency and capacity utilisation, or as stated differently, technical efficiency. Charnes et al. (1978), who first introduced this method, used the term Decision Making Unit (DMU) to refer to the 'entities' for which the efficiency scores were calculated. DEA involves the solution of a linear programming problem of the observed inputs and outputs. The ratio of total weighted output to the total weighted input provides the relative efficiency indicator for a DMU. Moreover, the linear programmer requires the selection of weights, such as the constraints experienced by each DMU (in our case, a quay crane), which are carefully considered in order to extract weights that are associated with the highest possible efficiency score for that particular DMU (AlRashidi, 2016).

The most basic way to measure efficiency is by computing a ratio between a unit of output and a unit of input:

Efficiency $=\frac{\text { Output }}{\text { Input }}$

However, the above circumstance is very rare as most organizations and firms operate with many inputs and outputs. Thus, this efficiency measure can be explained as follows:

Efficiency unit $j=\frac{\text { Total Weight Output }}{\text { Total Weight Input }}$

Which can be further explained as:

Efficiency unit $j=\frac{w i y i j+w 2 i y 2 i j}{v i x i j+v 2 i x 2 i j}$

\section{Charnes, Cooper and Rhodes (CCR) Model}

The CCR DEA model (1978) was developed based on Farrell's concept of relative efficiency, as described in the previous section. The authors considered homogeneous DMUs, which are organisations that function through common operational objectives and use similar inputs to generate similar outputs, as well as the constant return to scale (CRS) assumption that was assumed for this model. Subsequently, this model sometimes refers to the VRS-DEA model (Chaudhuri et al., 2009).

In a container terminal, throughput is an example of output, whereas move per hour and length of berth are examples of inputs. However, in this paper the inputs are number of crew and working tenure whereas, the outputs are number of accidents and man hours. By looking at the input and output, the aim of the CCR model is to measure the performance of a DMU (in the current study, number of crew) relative to the best observed practice in a sample of $n$ DMUs $(n=1,2, \ldots ., N)$, where each one of them utilises a vector of $i$ inputs $(i=1,2, \ldots, I)$ in order to produce a vector of $m$ outputs $(m=1,2, \ldots, M)$, which are the dimensions of the inputs and outputs vectors that are ( $\mathrm{I} \times 1)$ and $(\mathrm{M} \times 1)$, respectively. In order to better understand the CCR model, a mathematical representation is provided by the following linear programming problem for every DMU=DMUa:

$\operatorname{Max} E_{a}=\frac{\sum_{m=1}^{M} e_{m} Y_{m a}}{\sum_{i}^{I} c_{i} x_{i a}}$

Subject to following constrains:

$\frac{\sum_{m=1}^{M} e_{m} Y_{m a}}{\sum_{i}^{I} c_{i} x_{i a}} \leq ; n=1,2, \ldots \ldots . N$

$e_{m} \geq \varepsilon, C_{i \geq} \varepsilon ; I m=1,2, \ldots \ldots, M$

\section{Justification of Data and Selecting Variables}

The selected variables should reflect critical factors on board Offshore Supply Vessel (OSV) and Floating Loading and Offloading Unit (FSO) and be fully controlled by the crew on board 
or may be environmental factors. The factors chosen should clearly distinguish between comparable OSV and FSO and effectively serve the purposes of the analysis (Golony \& Roll, 1989). Sarkis (2002) discussed that the choice and number of inputs and outputs, as well as the DMU, influence the process of distinguishing between effective and inefficient units. The data used should be as accurate as possible to minimise measurement errors. To do this, the collected data is verified from various resources, for example, the maritime department and the operations department.

\section{Selection of Input and Output}

The choice of input and output affects the consistency of the results. Ignoring the relevant variables in the DEA results in inconsistent results. Careful selection of relevant factors has shown the usefulness of an effectiveness analysis tool for increasing productivity. The input criteria differ from the output. The input consists of all the resources that the DMU uses to get the output. Kersten et al. (2013) it is recommended to include dimensions for all the named resources to get a complete picture of the input data. In addition, the average number of crew members on board is taken into account. Information on the average number of crew members on board is vital, as this group plays an important role in daily work. Example is as in table 1 and this paper is using two (2) inputs and two (2) outputs as below:

Table 1: Variable required (input and output) in DEA

\begin{tabular}{llll}
\hline \multicolumn{2}{c}{ Input } & \multicolumn{2}{c}{ Output } \\
\hline Number of crew & Working Tenure & Accident Involved & Man Hours \\
\hline
\end{tabular}

Source: Author

\section{Inferential Analysis}

Table 2 shows detailed statistics based on input and output data. For the first input which is number of crew, maximum crew reported 63 persons and minimum reported was only 8 persons for one vessel. The average was 18.6 crews and standard deviation is 12.4055872 . Working tenure is the second Input which shows that maximum working tenure was 365 (complete one year) and minimum working tenure was only four (4) days. Average working tenure was 175. 7142857 days and standard deviation for working tenure is 136.4803641 .

The output data which is accident involved, it is reported that at least 1 accident was involved and the minimum accident is 0 , which brings that there is no accident reported. that at least one accident was reported and the minimum accident is zero, which brings that there is no accident reported. Average accidents for $35 \mathrm{DMU}$ were 0.2 , which means there is almost no accident for 35 DMU's in 2018 and standard deviation for accident involved is 0.4 . Man hours is the second output data required in this analysis, the maximum man hours for the year 2018 was 217,632 hours and the minimum man hours was 480 hours. Average man hours are 42,504 hours and standard deviation for man hours is 48,750 .

Table 3 depicts the correlation between working tenure and man hours shows high as its reading is 0.747731815 while correlation between number of crew and man hours shows medium at reading of 0.532711593 . The rest of the correlation shows low at reading 0.325827235 (accident involved and man hours).

There are a total of 5 numbers of DMU showing efficiency which is FSO Angsi, FSO Orkid, Sahan Beta 9, OLV 1 and IDS Cahaya. The remaining DMUs show inefficiency and require improvement.

Both Tables 4 and 5 are showing DMUs ranking based on their scoring points. Pelican 
Table 2: Input and output correlation

\begin{tabular}{ccccc}
\hline & \multicolumn{2}{c}{ Input } & \multicolumn{2}{c}{ Output } \\
\cline { 2 - 5 } & Number of crew & $\begin{array}{c}\text { Working } \\
\text { Tenure }\end{array}$ & $\begin{array}{c}\text { Accident } \\
\text { Involved }\end{array}$ & Man Hours \\
\hline Number of crew & 1 & 0.064 & 0.091 & 0.533 \\
Working Tenure & 0.0644 & 1 & 0.177 & 0.748 \\
Accident Involved & 0.091 & 0.177 & 1 & 0.326 \\
Man Hours & 0.533 & 0.748 & 0.326 & 1 \\
\hline
\end{tabular}

Table 3: Statistics on input and output data

\begin{tabular}{ccccc}
\hline & \multicolumn{2}{c}{ Input } & \multicolumn{2}{c}{ Output } \\
\cline { 2 - 4 } & Number of crew & Working Tenure & Accident Involved & Man Hours \\
\hline Max & 63 & 365 & 1 & 217,632 \\
Min & 8 & 4 & 0 & 480 \\
Average & 18.6 & 175.714 & 0.2 & $42,504.543$ \\
SD & 12.405 & 136.480 & 0.4 & $48,750.682$ \\
\hline
\end{tabular}

Gracious is show the most inefficiency (minimum is 0.1497 ) and FSO Angsi, FSO Orkid, Sahan Beta 9, OLV 1, and IDS Cahaya (maximum is 1) are showing the most efficient DMUs. Based on the slack result table above, the 5 numbers of efficient DMUs are FSO Angsi, FSO Orkid, Sahan Beta 9, OLV 1, and IDS Cahaya showing 0 in all input and output. That means all DMUs have no issues on the input (number of crew and working tenure) and output (accident involved and man hours). No improvement is required on input and output in order to become an efficient DMU.

Armada Tuah 21 is ranked sixth with efficiency of 0.87913 . It has no issue on the input as it is 0 . However, she has an issue on the output whereby accident involved shows a value of 0.383 . According to projection result, Armada Tuah 21 percentage likelihood to get involved in accident is 52.022 percent. Hence, in order for her to become efficient, she has to increase the man hours up to 36199.57 hours or 13.749 percent so that accidents will not happen on board the vessel.

As for Pelican Gracious, she is the last in ranking. Based on the slack result, it shows that she has an issue on the output where the accident involved is 0.805 and man hours of 2002.504. In order for her to avoid any accident on board, she has to increase her man hours up to 15470.66 hours or $667.394 \%$. 
Table 4: Ranking score and slack result

\begin{tabular}{|c|c|c|c|c|c|c|c|}
\hline & & & & Slack & Slack & Slack & Slack \\
\hline$\dot{z}$ & $\stackrel{\vec{b}}{\vec{b}}$ & 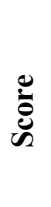 & 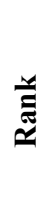 & 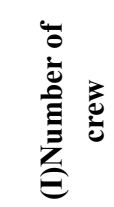 & $\overbrace{}^{\infty}$ & 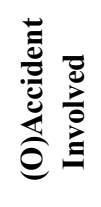 & \\
\hline
\end{tabular}

\begin{tabular}{|c|c|c|c|c|c|c|c|}
\hline 1 & FSO Angsi & 1 & 1 & 0 & 0 & 0 & 0 \\
\hline 2 & FSO Orkid & 1 & 1 & 0 & 0 & 0 & 0 \\
\hline 3 & FSO PM3 CAA & 0.78119 & 9 & 0 & 0 & 1.96 & 0 \\
\hline 4 & PTSC Hai Phong & 0.82883 & 8 & 0 & 0 & 1.385 & 0 \\
\hline 5 & PTSC Huong Giang & 0.74433 & 11 & 0 & 0 & 1.445 & 0 \\
\hline 6 & PTSC Lam Kinh & 0.73732 & 13 & 0 & 0 & 1.463 & 0 \\
\hline 7 & Setia Kental & 0.74121 & 12 & 0 & 0 & 1.354 & 0 \\
\hline 8 & Setia Tegap & 0.73732 & 13 & 0 & 0 & 1.412 & 0 \\
\hline 9 & Armada Tuah 21 & 0.87913 & 6 & 0 & 0 & 0.383 & 0 \\
\hline 10 & Armada Tuah 26 & 0.84267 & 7 & 0 & 0 & 0.467 & 0 \\
\hline 11 & Alkahfi Alisha & 0.42623 & 20 & 0 & 0 & 0.857 & 14167.77 \\
\hline 12 & Alkahfi Aminah & 0.48078 & 19 & 0 & 0 & 0.865 & 14729.57 \\
\hline 13 & Alkahfi Asura & 0.32321 & 26 & 0 & 0 & 0.843 & 12335.14 \\
\hline 14 & SK Line 715 & 0.41167 & 21 & 0 & 0 & 2.123 & 482.592 \\
\hline 15 & SK Deep Sea & 0.73047 & 15 & 0 & 0 & 3.176 & 0 \\
\hline 16 & Sahan Beta 9 & 1 & 1 & 0 & 0 & 0 & 0 \\
\hline 17 & Bahtera Pertiwi & 0.324 & 25 & 0 & 0 & 1.708 & 1428.234 \\
\hline 18 & Pelican Gracious & 0.14969 & 35 & 0 & 0 & 0.805 & 2002.504 \\
\hline 19 & Bahtera Hadar & 0.30952 & 29 & 0 & 0 & 1.618 & 3577.145 \\
\hline 20 & Tanjung Biru 1 & 0.22201 & 30 & 1.5 & 0 & 1.25 & 413.513 \\
\hline 21 & Executive Courage & 0.71736 & 17 & 0 & 0 & 0.971 & 0 \\
\hline 22 & Executive Stride & 0.3122 & 28 & 0 & 0 & 1.823 & 4579.02 \\
\hline 23 & Executive Honour & 0.3456 & 24 & 0 & 0 & 1.727 & 3812.002 \\
\hline 24 & JM Tabah & 0.72485 & 16 & 0 & 0 & 1.593 & 0 \\
\hline 25 & JM Abadi & 0.75966 & 10 & 0 & 0 & 1.514 & 0 \\
\hline 26 & Jati 3 & 0.16779 & 33 & 0 & 0 & 0.816 & 5636.937 \\
\hline 27 & Jati 4 & 0.16779 & 33 & 0 & 0 & 0.816 & 5636.937 \\
\hline 28 & Jati 5 & 0.20678 & 31 & 0 & 0 & 0.824 & 7824.987 \\
\hline 29 & Perdana Horizon & 0.35979 & 23 & 0 & 0 & 1.734 & 4552.245 \\
\hline 30 & Salvin Princess & 0.65015 & 18 & 4.564 & 0 & 3.087 & 0 \\
\hline 31 & Tanjung Piai 2 & 0.39959 & 22 & 0 & 0 & 2.023 & 1043.169 \\
\hline
\end{tabular}




\begin{tabular}{|c|c|c|c|c|c|c|c|}
\hline 32 & Aisyah Aimes 4 & 0.17622 & 32 & 0 & 0 & 1.004 & 1522.967 \\
\hline 33 & Sapura Achiever & 0.31715 & 27 & 0 & 0 & 2.003 & 668.728 \\
\hline 34 & OLV 1 & 1 & 1 & 0 & 0 & 0 & 0 \\
\hline 35 & IDS Cahaya & 1 & 1 & 0 & 0 & 0 & 0 \\
\hline
\end{tabular}

Table 5: Ranking score with projection results

\begin{tabular}{|c|c|c|c|c|c|c|c|c|c|c|c|c|}
\hline & & & & 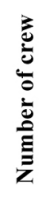 & & & 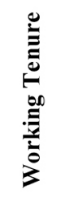 & & & 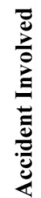 & & \\
\hline$\dot{z}$ & 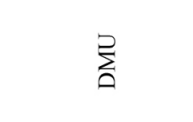 & 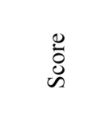 & 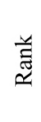 & 节 & 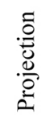 & 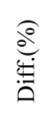 & $\stackrel{\frac{\pi}{\pi}}{0}$ & 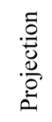 & 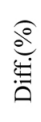 & 荶 & 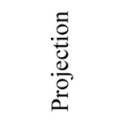 & 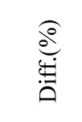 \\
\hline 1 & FSO Angsi & 1 & 1 & 53 & 53 & 0 & 365 & 365 & 0 & 1 & 1 & 0 \\
\hline 2 & FSO Orkid & 1 & 1 & 30 & 30 & 0 & 365 & 365 & 0 & 1 & 1 & 0 \\
\hline 3 & FSO PM3 CAA & 0.78119 & 9 & 28 & 28 & 0 & 365 & 365 & 0 & 0 & 0 & 0 \\
\hline 4 & PTSC Hai Phong & 0.82883 & 8 & 18 & 18 & 0 & 365 & 365 & 0 & 0 & 0 & 0 \\
\hline 5 & $\begin{array}{l}\text { PTSC Huong } \\
\text { Giang }\end{array}$ & 0.74433 & 11 & 17 & 17 & 0 & 310 & 310 & 0 & 0 & 0 & 0 \\
\hline 6 & PTSC Lam Kinh & 0.73732 & 13 & 15 & 15 & 0 & 365 & 365 & 0 & 0 & 0 & 0 \\
\hline 7 & Setia Kental & 0.74121 & 12 & 13 & 13 & 0 & 365 & 365 & 0 & 0 & 0 & 0 \\
\hline 8 & Setia Tegap & 0.73732 & 13 & 14 & 14 & 0 & 365 & 365 & 0 & 0 & 0 & 0 \\
\hline 9 & Armada Tuah 21 & 0.87913 & 6 & 13 & 13 & 0 & 202 & 202 & 0 & 1 & 1.52022 & 52.022 \\
\hline 10 & Armada Tuah 26 & 0.84267 & 7 & 13 & 13 & 0 & 163 & 163 & 0 & 1 & 1.653619 & 65.362 \\
\hline 11 & Alkahfi Alisha & 0.42623 & 20 & 8 & 8 & 0 & 211 & 211 & 0 & 0 & 0 & 0 \\
\hline 12 & Alkahfi Aminah & 0.48078 & 19 & 8 & 8 & 0 & 238 & 238 & 0 & 0 & 0 & 0 \\
\hline 13 & Alkahfi Asura & 0.32321 & 26 & 8 & 8 & 0 & 160 & 160 & 0 & 0 & 0 & 0 \\
\hline 14 & SK Line 715 & 0.41167 & 21 & 21 & 21 & 0 & 92 & 92 & 0 & 0 & 0 & 0 \\
\hline
\end{tabular}




\begin{tabular}{|c|c|c|c|c|c|c|c|c|c|c|c|c|}
\hline 15 & SK Deep Sea & 0.73047 & 15 & 36 & 36 & 0 & 137 & 137 & 0 & 0 & 0 & 0 \\
\hline 16 & Sahan Beta 9 & 1 & 1 & 9 & 9 & 0 & 365 & 365 & 0 & 1 & 1 & 0 \\
\hline 17 & Bahtera Pertiwi & 0.324 & 25 & 17 & 17 & 0 & 35 & 35 & 0 & 0 & 0 & 0 \\
\hline 18 & Pelican Gracious & 0.14969 & 35 & 8 & 8 & 0 & 21 & 21 & 0 & 0 & 0 & 0 \\
\hline 19 & Bahtera Hadar & 0.30952 & 29 & 16 & 16 & 0 & 71 & 71 & 0 & 0 & 0 & 0 \\
\hline 20 & Tanjung Biru 1 & 0.22201 & 30 & 14 & 12.5 & -10.714 & 5 & 5 & 0 & 0 & 0 & 0 \\
\hline 21 & $\begin{array}{l}\text { Executive } \\
\text { Courage }\end{array}$ & 0.71736 & 17 & 18 & 18 & 0 & 105 & 105 & 0 & 1 & 2.364653 & 136.465 \\
\hline 22 & Executive Stride & 0.3122 & 28 & 18 & 18 & 0 & 92 & 92 & 0 & 0 & 0 & 0 \\
\hline 23 & Executive Honour & 0.3456 & 24 & 17 & 17 & 0 & 103 & 103 & 0 & 0 & 0 & 0 \\
\hline 24 & JM Tabah & 0.72485 & 16 & 17 & 17 & 0 & 365 & 365 & 0 & 0 & 0 & 0 \\
\hline 25 & JM Abadi & 0.75966 & 10 & 17 & 17 & 0 & 365 & 365 & 0 & 0 & 0 & 0 \\
\hline 26 & Jati 3 & 0.16779 & 33 & 8 & 8 & 0 & 61 & 61 & 0 & 0 & 0 & 0 \\
\hline 27 & Jati 4 & 0.16779 & 33 & 8 & 8 & 0 & 61 & 61 & 0 & 0 & 0 & 0 \\
\hline 28 & Jati 5 & 0.20678 & 31 & 8 & 8 & 0 & 90 & 90 & 0 & 0 & 0 & 0 \\
\hline 29 & Perdana Horizon & 0.35979 & 23 & 17 & 17 & 0 & 131 & 131 & 0 & 0 & 0 & 0 \\
\hline 30 & Salvin Princess & 0.65015 & 18 & 41 & $\begin{array}{c}36.43 \\
65\end{array}$ & -11.13 & 18 & 18 & 0 & 0 & 0 & 0 \\
\hline 31 & Tanjung Piai 2 & 0.39959 & 22 & 20 & 20 & 0 & 91 & 91 & 0 & 0 & 0 & 0 \\
\hline 32 & Aisyah Aimes 4 & 0.17622 & 32 & 10 & 10 & 0 & 17 & 17 & 0 & 0 & 0 & 0 \\
\hline 33 & Sapura Achiever & 0.31715 & 27 & 20 & 20 & 0 & 18 & 18 & 0 & 0 & 0 & 0 \\
\hline 34 & OLV 1 & 1 & 1 & 63 & 63 & 0 & 64 & 64 & 0 & 0 & 0 & 0 \\
\hline 35 & IDS Cahaya & 1 & 1 & 10 & 10 & 0 & 4 & 4 & 0 & 1 & 1 & 0 \\
\hline
\end{tabular}




\section{Conclusion}

This paper attempt is to measure accident rates on board based on human factor. This is because the number of incidents seems to fluctuate and does not show a stable number. The number of incidents decreased from 2010 to 2014, but it started to increase from 2014 to 2016 and again, the number of incidents slowly decreased until 2018. Because of this unpredictable numbers of incidents, it is a major concern on why this study should be undertaken.

In this paper, 35 vessels had been screened in order to assess crew competency. The researcher uses DEA technique in order to measure the efficiency of each OSVs and FSOs. The researcher also attempts to adopt only DEA- BCC in order to capture the algorithm. The result will seek improvement of inefficiency of OSVs and FSOs.

Researcher agrees with Bratianu (2016) statement which is "Efficiency and Quality cannot be achieved without competence". It signifies that competence is essential for both efficiency and quality. A product can be produced efficiently without a good quality. Quality can be obtained without any specific efficiency. From the screening, there are five (5) vessels (FSO Angsi, FSO Orkid, Sahan Beta, OLV 1 and IDS Cahaya) that are operated efficiently, while 30 vessels are not operated efficiently or at their standard. From this result, these 30 vessels need to revise their safety Standard Operating Procedures (SOP) and policies in order to increase their safety performance and awareness. This way, vessels can reduce accident and operate efficiently and competently.

\section{Acknowledgements}

The research is conducted under Ministry of Higher Education (MOHE) research grant vote no 59481 with the code FRGS/1/2017/TK08/UMT/02/5 and University of Malaysia Terengganu (UMT) for research facilities.

\section{References}

Akten, N. (2006). Shipping accidents: A serious threat for marine environment. Journal of the Black sea/Mediterranean environment, 12(3), 269-304.

Akten, N., \& Gonencgil, B. (2002). The turkish straits: rights and obligations of vessels to transit. In rights and obligations of vessels transiting through the turkish straits. Institute of Marine Sciences and Management, 21(June), 3-4.

Al-Rashidi, A. (2016). Data envelopment analysis for measuring the efficiency of head trauma care in England and Wales. Doctoral dissertation, Salford University.

Alliance Societas Europaean. (2013). Alliance global corporate and specialty AG successfully adopt new legal structure of societas Europaea (SE). Retrieved from https://www.allianz.com/en/press/news/ company/point_of_view/news-2013-11-19. html

Antonsen, S. (2009). The relationship between culture and safety on offshore supply vessels. Safety Science, 47(8), 1118-1128.

Baalisampang, T., Abbassi, R., Garaniya, V., Khan, F., \& Dadashzadeh, M. (2018). Review and analysis of fire and explosion accidents in maritime transportation. Ocean Engineering, 158, 350-366.

Boyatzis, R. E., Stubbs, E. C., \& Taylor, S. N. (2002). Learning cognitive and emotional intelligence competencies through graduate management education. Academy of Management Learning \& Education, 1(2), 150-162.

Bratianu, C. (2016). Knowledge dynamics. Management Dynamics in the Knowledge Economy, 4(3), 323-337. 
Ayden, B. \& Ceylan, A. (2008). The employee satisfaction in metalworking manufacturing:,How do organisational culture and organisational learning capacity jointly affect it? Journal of Industrial Engineering and Management, 1(02), 143168.

Carr, D. (2000). Education, profession and culture: Some conceptual questions. British Journal of Educational Studies, 48(3), 248268.

Chansiri, W. (2008). Core Competency of Public Universities Supporting-Line Administrators in Thailand (Doctor of Education Thesis). Mahasarakham University, Mahasarakham.

Charnes, A., Cooper, W. W., \& Rhodes, E. (1978). Measuring the efficiency of decision making units. European Journal of Operational Research, 2(6), 429-444.

Chaudhuri, S. R., Karmakar, D., Na, U. J., \& Shinozuka, M. (2009). Seismic performance evaluation of container cranes. In Improving the Seismic Performance of Existing Buildings and Other Structures (pp. 379388).

Dekker, S. (2011). Drift into Failure: From Hunting Broken Components to Understanding Complex Systems. London: Ashgat.

Drucker, P. F. (1973). Management: Tasks, Responsibilities, and Practices. New York: Harper \& Row. (pp. 45-46).

Drucker, P. F. (1985). Innovation and Entrepreneurship: Practice and Principles. University of Illinois at UrbanaChampaign's Academy. Entrepreneurial Leadership Historical Research Reference in Entrepreneurship. Retrieved from https:// ssrn.com/abstract $=1496169$

Golony, B., \& Roll, Y. (1989). An application procedure for DEA. International Journal of Management Science, 17(3), 237-250.

Greengard, S. (1999). Competency management delivers spectacular corporate gains. Workforce, 78(3), 104-105.
Hanzu-Pazara, R., Barsan, E., Arsenie, P., Chiotoriou, L., \& Raicu, G. (2008). Reducing of maritime accidents caused by human factors using simulators in training process, Journal of Maritime Research, 5(1), 3-18.

Harati, A., Wall, A., Brooks, P. \& Wang, J. (2006). Automatic Identification System (AIS): A Human Factors Approach, the Nautical Institute Website, AIS Forum, and Technical Feedback, UK.

Hudson, P. (2007). Implementing safety culture in a major multi-national. Safety Science, 45, 697-722.

IMO (International Maritime Organisation) (1996). Reports on Marine Causalities. Harmonized Reporting Procedures, annex 3, Draft MSC/MEPC Circular, IMO FS14/18.

Ismila C. I., Mohamad F. A., Shaiful, B. I., \& Norhayati, M. Z. (2019) A Study of Human Error Factors on Maritime Accident Rates in Maritime Industry. Asian Academy of Management Journal, 24(2), 17-32.

Kersten, W., Blecker, T. \& Ringle, C. M. (2013). Pioneering Solutions in Supply Chain Performance Management. Lohmar: Josel Eul Verlag (Supply Chain, Logistics and Operations Management, 17). ISBN 978-38441-0267-3

Krintiansen, S. (2004). Maritime transportation: Safety Management and Risk Analysis. Oxford: Elsevier Science \& Technology.

Lai, L. (2011). Employees' perceptions of the opportunities to utilize their competences: exploring the role of perceived competence mobilization. International Journal of Training and Development, 15(2), 140-157.

Mankabady, S. (1987). The International Maritime Organization Vol. 2: Accidents at sea. London: Taylor \& Francis Ltd.

Monteiro, P. C. (2015). Performance Analysis in Port Container Terminals.

Mullai, A., \& Paulsson, U. (2011). A grounded theory model for analysis of marine accidents. Accident Analysis \& Prevention, 43(4), 1590-1603. 
NcCleland, D. (1973). Testing for competence rather than for "intelligence". American Psychologist. Harvard University.

Pidgeon, N., \& O'Leary, M. (1994). Organizational safety culture: Implications for aviation practice. Aviation Psychology in Practice, 21-43.

Reason, J. (1990). Human Error. Cambridge: Cambridge University Press.

Reason, J. (1997). Managing the Risks of Organizational Accidents. Aldershot, UK: Ashgate Publishing Company.

Sarkis, J., (2002), Preparing Your Data for DEA, Productivity Analysis in the Service Sector with Data Envelopment Analysis, 2nd Edition. Retrieved from www.clarku. edu/ jsarkis/SarkisChapter.doc, assessed on 22.07.13
Spencer, L. M., \& Spencer, S. M. (1993). Competence at work: Models for superior performance. New York: John Wiley \& Sons.

Weick, K. E., \& Sutcliffe, K. M. (2007). Managing the Unexpected: Resilient Performance in an Age of Uncertainty. Jon Wiley \& Sons.

Weintrit, A. (2009). Marine Navigation and Safety of Sea Transportation. CRC Press, Balkema. 